

\section{A Simulation Set-up to Observe the Effects of the Emotional Factor on Capital Markets}

\author{
Belma Ozturkkal Ph.D
}

\section{Introduction}

Emotional aspects of decision-making process have been analyzed in the psychology quite in depth, however the analysis for financial decisions was not the point of concern until recently. In finance the analysis of the capital markets and the agency theory has been an important area of research, as the principal and the agent have different motivations since conflict of interest between two parties arises. Shleifer (2000) models investor sentiment where investor deficiencies are present and points Kahneman and Tversky studies of representativeness, conservatism and so forth. Shefrin (2002) reports mispricing, due to overconfidence and anchoring on investor reactions to new information of asset prices. Investor's interaction with emotions changes their tolerance to risk. We do not observe many experimental studies for the measurement of variation of behavior of the manager and shareholder.

This study is motivated by the shareholder and manager mechanism on experimental set-up simulating a real market environment, where the individual self-reported emotions are analyzed from the perspective of investors and managers. The capital market environment is replicated with one asset on a 10 round finite market, where manager declares dividend and investor bids for the asset. The price of the asset is calculated by BeckerDeGroot Marschak Method, where the price of the asset is calculated with a random number and compared to the price bid by the investor. The asset is only purchased by the investor, if his price is higher than the random number generated in the auction, otherwise the investor does not purchase any shares and receives no dividends of future periods. There is quite a few research in psychology investigating the emotions and decision-making, hence there is not a link of these studies to finance. My contribution is that the emotions and financial decisions are investigated from a different perspective with this experimental study. This study is motivated by the urge to establish and prove a link for the basic emotions where such a relation was poven for "happiness". The results show that there is statistically significant positive link between a person's happiness and his profitability in capital market environment.

This study analyzes the emotional aspect especially the "happy mood" of surplus division among managers and investors in an experimental set-up. The emotional state with the conflict of interest and power structures' is analyzed, to see the effect of different payout mechanisms on Willingness to Pay (WTP). The aim of the study is to establish a directional link between emotions and profitability in capital markets than having a full fledged model to explain profitability in numbers with emotions.

Prior research by Camerer, Loewenstein and Prelec (2005) distinguish between controlled and automatic processes on human behavior. Singer and Fehr (2005) note that normal adults can menthalize and empathize as an important feature for self-interested decision to enable people to predict other's decisions more accurately. MRI scanner study showed some parts of brain were active when acivated empathizing pain of others. Others' intensions, beliefs and thoughts are based on emotions and it is important to predict others' behavior to meet individual goals. The empathic people can predict others' motives and actions.

A finding by Powell (1970) states that economic model can predict monkey behavior with 
90\% probability. Humans tally probabilities, expected gain and cost of work to get reward of simple choice decisions. Hence, there are shortcomings of human psychology and behavior. Some examples are noted by Charness and Gneezy (2003) such as some behavioral deficiencies as ambiguity aversion to avoid unclear circumstances, illusion of control arises if involvement is present people's confidence have in a favorable outcome, myopic loss aversion is loss aversion and tendency to evaluate outcomes frequently and overconfidence increases with task complexity and decreases with uncertainty. Another finding on decision-making is by Rustichini (2005) that ambiguity premium declines as subjects repeat their choices. People slowly adjust to ambiguity, however they do not adjust to risk.

In the study, the interdisciplinary analysis of the investor shareholder relationship and their behavior mechanism under different emotions is demonstrated. My analysis continues with Literature Review and Experimental Design and Methodology, followed by the Results section and concludes.

\section{Literature Review}

The decision-making process analyzed in depth by the psychologists is more of an interest for the finance field as well, since it is observed that some forms of emotion have effect on outcomes such as profitability and bidding prices. This was the case in real market environment, especially on panic and bubble formation cases such as in the year 2000 and 2008 in the US. Easley, David and Aldo Rustichini (1998) suggest that that the individuals increase the actions where the payoff is high. Hofbauer and Schlag (2000) reports that the role of imitation in a population is highly important. Individuals may have a set of preferences of actions and they update the probabilities according to outcomes and revise systematically even if they are not rational. (a form of rational behaviorism) The systematic procedures work if updating is not biased.

A group of studies focuses on the functions of the brain and emotions. Some other concentrate on the choices with certain emotions. Cassidy (2006) notes that there are multiple systems under the brain and most of the time they compete with each other. He notes that the brain doesn't like ambigious situations and people who are less fearful make better investors. Adler (2004) states that researchers use fMRI machines show how it works inside the brain and brain's insular cortex is associated with negative emotions such as anger and disgust. Monkey's follow highest social ranking troop member similar to humans. Engelmann, Capra and Noussair (2009) observes fMRI scans change for participants on a choice and lottery without expert advice, where these brain areas are not active with the condition of expert financial advice. Johnson and Tversky (1983) found that good mood is associated with optimistic judgments and bad mood with pessimistic judgments and that people are influenced by affect induced and on an experiment who read sad articles on newspaper made pessimistic risk estimates on causes of death compared to people who read happy articles.

Capra (2004) reports that emotions play a role in determining choice. Ther research results show that there is difference between good and bad mood choices. Happier subjects are more strategic and more helpful and altruistic. The finding shows that positive affect enhances reasoning and arousal level of good mood people are higher and they are more confident and alert. Bad mood people are more trustworthy than good mood people. Capra, Meer, Lanier (2010) investigated the effect of moods on decisions and find that positive mood generates an upward bidding bias. They designed a survey with a quiz and then used mood induction to elicit different state of mood where people recalled a happy or sad event. They found that no major differences observed for negative and neutral 
processes, however positive mood affected decision process. The subjects in positive mood over-bid the prices. They report that mood affects selfperceptions and judgment, where positive affect increases efficient reasoning and creativity and negative affect increases self-focus. They prove good mood releases dopamine, however created mood by unexpected occurrence may cause distortions. The finding of the study was that positive mood increases willingness to pay. There is also contradictary evidence that negative mood, sadness may increase willingness to pay.

Lerner, Small and Loewenstein (2004) report that anger evokes more optimistic risk estimates and risk-seeking choices and fear does the opposite. They find that negative moods supress value. They use $3 \times 2$ between subjects design (disgust-Trainspotting, sadness-The Champ, neutral-National Geographic Special) wher subjects endowed an object and watched a video clip for mood induction process for 4 minutes and after that they wrote a reponse and on ther second study they had to choose a sell or choice procedure. Additionally, they were asked to report their feelings. The finding is that sadness decreased selling prices and increased choice prices, disgust reduced both prices.

The research on emotions and financial decision-making process started by Lo, Repin (2002) where they studied ten professional traders and for the rational decision-making process and find emotional response, skin conductance and cardiovascular variables (heart rate, respiration rate, ..) when price or trend changes.

Lo, Repin and Steenbarger (2005) work with 80 day-traders on another study through surveys and find a negative correlation between emotional activity and successful trading. They didn't find a certain skill set of characteristics which can identify the successful trader. They note that automatic responses such as fear and greed are more powerful than higher-level responses. It is shown that emotional reactions short-circuit complex decision making as well as affective states (sunshine, weather etc.) are related to market activity.

Witteloostujin and Muehlfield (2008) analyze locus of control, maximizing tendency, regret disposition, self-monitoring, sensation seeking, and type A-B behavior. Studies linked risk attitude to locus of control. High self-monitors achieve superior trading performance only on male subjects. Trading frequency and performance is found to be negatively correlated. They tested six personality traits on 34 students: locus of control, maximizing tendency (maximizing as opposed to satisficing), regret disposition (the extent the individual is sensitive to regret), self-monitoring (observe and control self behavior), sensation seeking (willingness to take risks) and type A-B behavior. People with internal locus of control think they can influence their environment, people with external locus of control think they are passive and events are beyond their control. Type A is aggressive and impatient, competitive and hostile. Those who have not such behavioral patterns are called type B. They experiment on z-tree with multiple short-lived assets of lottery ticket and cash assset, in a double-auction market for 24 periods. Sensation seeking and self-monitoring was positively correlated. Gender was negatively correlated with locus of control. Women trade less and trading experience reduces trading frequency. There is less frequent trading of people high in regret disposition and low in sensation seeking. Type trait lowers trading frequency. Selfmonitoring people marginally select themselves to market maker role. Type A people showed lower level of arbitraging.

Loewenstein (1996) find anger may result from perceived insult, shame or embarrasment and is typically unpleasant and increases one's taste for aggressive actions. They also find uncontrolled anger produces impulsive actions or immobilization. Additionally, extreme fear produces panic and immobilization. Loewenstein, 
Weber and Welch (2001) analyze anticipatory (immediate-fear, anxiety, etc.) and anticipated (future) reactions. It is shown that people in good mood are reluctant to gamble in order not to lose the good mood.

Van Boven (2005) finds fear of embarrassment is an important determinant of social behavior and people underestimate the effect on their own preferences and decisions. Emotional arousal, particularly fear and anxiety narrow attention. He examined illusion of courage and asked 174 undergraduates other people's interest to dance and perform a mime. Some of them were real performers other were hypothetical. They overestimated other people's willingness. Prediction

\section{III.Experimental Design and Methodology}

The study involved 74 student subjects from a major public university in the southern United States. No subject participated in multiple sessions. This study was run in 10 sessions. Each session used one of three treatments explained in the Appendix and the experiment lasted about 30 minutes including instruction time. Each session also paired students together as manager and investor. Each manager and each investor were initially given 500 experimental tokens (200 token $=\$ 1$ ) and no shares. Shares purchased throughout the experiment carried no value at the end of the experiment. The capital market environment is replicated with one asset, where manager declares dividend and investor bids for the asset. The price of the asset is calculated by BeckerDeGroot Marschak Method, where the price of the asset is calculated with a random number and compared to the price bid by the investor. The asset is only purchased by the investor, if his price is higher than the random number generated in the auction, otherwise the investor does not purchase any shares and receives no dividends of future of others are based on one's own preferences and decisions and underestimation of the power of emotion is a fundamental error in social judgment. People systematically underestimate fear of embarrasment's impact on other people's preferences and decisions. Anxious people interpret situations threatening. Anxiety was positively correlated with risk aversion. Raghunathan and Pham (1999) found that anxiety increased preference for low risk and low reward options, where induced sadness resulted the opposite. Keltner (2000) found that fearful individuals make relatively pessimistic risk assessments and riskaverse choices.

periods. The manager and the investor were each compensated according to their final profit at the end of the experiment. Shares purchased by the investor in each round continued to earn the applicable dividend of each successive round as decided by the manager. The $\mathrm{z}$-Tree program (Fischbacher, 2007) was used as the user interface for the computerized experiments. Subjects earned anywhere from $\$ 2$ to $\$ 6$ each for about 10-15 minutes of participation. SAS program was used for econometric analysis and the target was to establish a directional link between emotions and profitability of investors and managers in capital markets than having a model to explain profitability in numbers.

Smith, van Boening and Wellford (2000) evidence that experienced investors are less likely to produce bubble formation compared to inexperienced investors and people are adaptive to changes in unchanging environment. Hence, investors if unexperienced do not use backward induction and profit maximization methods. There were three treatments with 10 periods each. In Treatment "Dividend Before," the subject in the role of manager determined and announced the dividend before the investor had the opportunity to buy in each period. In Treatment "Dividend After," 
the subject in the role of manager determined and announced the dividend after the trade decision was completed by the investor in the period. In Treatment "Investor Control" the investor decided on the dividend before making the trade decision. All other aspects were kept identical across treatments.

The subjects are asked to fill the survey in the Appendix in order to have information about their emotional status at the time of the experiment and their demographic characteristics. This information then was considered to find possible link with the profitability of the subjects in the experiment set-up. The summarized information of the emotion of the subjects is reported on Table 1 and 2. The average age of the subjects is 23.8 ranging between 21 and 41 and $39.7 \%$ of the subjects are male. $16.2 \%$ of the subjects hold business or economics major or masters degree. The self-reported emotional status is inclined to be observed as "happy" in comparison to other emotions such as "sad", "worried", "excited", "angry". These emotions are sclaed on a 1-7 and the maximum level 1-2 or 6-7 are considered for the relevant answer.

Table 1: Self Reported Emotional State

\begin{tabular}{lr} 
Emotion & \\
\hline happy & $50,4 \%$ \\
sad & $7,1 \%$ \\
angry & $5,4 \%$ \\
fearful & $3,6 \%$ \\
worried & $8,9 \%$ \\
confident & $16,1 \%$ \\
excited & $16,1 \%$ \\
self-controlled & $28,6 \%$ \\
\hline
\end{tabular}

Table 2: Characteristic Information

Self Reported Variable

\begin{tabular}{lr}
\hline Optimist & $50,5 \%$ \\
One happy or sad occurrence in the last two days & $53,7 \%$ \\
Emotional & $10,7 \%$ \\
Introverted & $8,9 \%$ \\
Loses Temper easily & $12,5 \%$ \\
Good to deal with Uncertainty & $44,6 \%$ \\
Risk-Taker & $32,1 \%$ \\
Bought Stock before & $34,5 \%$ \\
\hline
\end{tabular}

Table 2 reports the summarized self-reported characteristics of the subjects in consider themselves as optimistic, emotional, introverted etc. $50 \%$ of the subjects consider themselves as optimists on a 1-2 or 6-7 on a 1-7 choice level scale.

The method for the analysis is ordinary least square regression where profitability of the subjects a dependent variable is regressed with emotional status and demographic characteristics of the subjects as the independent variables. The regression is first run on the whole sample and then seperately on the group of managers and a group of investors.

The regression equation is:

Total Profit $=\mathrm{Cj}+\sum$ Coefficient $\mathrm{ij} *$ Mood ij

Mood i = One mood factor selected from Happy, Sad, Angry, Fear, Worry, Confident, Excited, SelfControl

The Table 1 reports self-reported emotional state of the subjects. 


\section{Results}

The Table 3 summarizes the descriptive statistics of the variables. The regression of gender as independent variable and graduation major are not significant for the sample profitability. The subjects defining themselves as emotional does not have any significant effect on profitability. The subjects who define themselves as risk-taker do not have any significant effect on profitability as well. Previous stock purchase history, age are not significantly important on profitability.Some of the regressions do not show high significance. This may be the outcome of the study or the sample may not be enough to analyze these variables. It may be interesting to repeat the study with another sample where the results may be investigated on a more diverse group with a larger sample.

Table 3: Descriptive Statistics

\begin{tabular}{|c|c|c|c|c|c|}
\hline Variable & $\mathbf{N}$ & Mean & Std Dev & Minimum & Maximum \\
\hline Age & 40 & 23.7750000 & 3.3473104 & 21.0000000 & 41.0000000 \\
\hline HAPPY & 56 & 0.5000000 & 0.5045250 & 0 & 1.0000000 \\
\hline SAD & 56 & 0.0714286 & 0.2598701 & 0 & 1.0000000 \\
\hline ANGRY & 56 & 0.0535714 & 0.2272078 & 0 & 1.0000000 \\
\hline FEAR & 56 & 0.0357143 & 0.1872563 & 0 & 1.0000000 \\
\hline WORRY & 56 & 0.0892857 & 0.2877364 & 0 & 1.0000000 \\
\hline CONDID & 56 & 0.1607143 & 0.3705910 & 0 & 1.0000000 \\
\hline EXCI & 56 & 0.1607143 & 0.3705910 & 0 & 1.0000000 \\
\hline SELFC & 56 & 0.2857143 & 0.4558423 & 0 & 1.0000000 \\
\hline OPTIMIST & 56 & 0.5000000 & 0.5045250 & 0 & 1.0000000 \\
\hline HAPPYSAD & 56 & 0.5357143 & 0.5032363 & 0 & 1.0000000 \\
\hline EMO & 56 & 0.1071429 & 0.3120939 & 0 & 1.0000000 \\
\hline INTRO & 56 & 0.0892857 & 0.2877364 & 0 & 1.0000000 \\
\hline TEMPER & 56 & 0.1250000 & 0.3337119 & 0 & 1.0000000 \\
\hline GOODUNC & 56 & 0.4464286 & 0.5016207 & 0 & 1.0000000 \\
\hline RISK & 56 & 0.3214286 & 0.4712514 & 0 & 1.0000000 \\
\hline TotalProfit & 68 & 556.4264706 & 156.1875371 & 0 & 1173.00 \\
\hline
\end{tabular}


Table 4 shows the regression results that a subject's self-reported happiness has a more significant positive effect on total profit compared to other emotions. Furthermore, fear and feeling excited seem to have also a positive effect on the total profit of the subject. As the emotions are not expected to explain the profitability as a whole, the results should be interpreted as satisfactoryu since happiness and profitability have a statistically significan relationship compared to other emotions. The adjusted $\mathrm{R} 2$ is $28,4 \%$.

\begin{tabular}{lccccc}
\multicolumn{6}{c}{ Table 4: Regression of Total Profit on Emotional State } \\
\multicolumn{1}{c}{ Variable } & Parameter & Standard Error & t Value & P \\
\hline Intercept & 448,5 & 32,0 & $* * *$ & 14,0 & 0,0001 \\
Happy & 145,8 & 33,5 & $* * *$ & 4,4 & 0,0001 \\
Sad & 93,0 & 67,9 & & 1,4 & 0,1777 \\
Angry & $-66,5$ & 77,6 & & $-0,9$ & 0,3958 \\
Fear & 184,8 & 84,4 & $* *$ & 2,2 & 0,0335 \\
Worry & $-30,8$ & 52,9 & & $-0,6$ & 0,5634 \\
Confident & 44,3 & 39,5 & & 1,1 & 0,2679 \\
Excited & 80,3 & 43,2 & $*$ & 1,9 & 0,0693 \\
Self-Control & 53,3 & 32,6 & & 1,6 & 0,1084 \\
\hline R-Square & $38,90 \%$ & & & \\
Adj. R-Square & 28,4 & & & & \\
F Value & 3,7 & & & \\
p Value & 0,0019 & & &
\end{tabular}

Table 5: Regression of Investor's Total Profit on Emotional State

\begin{tabular}{lccccc}
\multicolumn{1}{c}{ Variable } & \multicolumn{2}{c}{ ParameterStandard Error } & $\mathrm{t}$ Value & $\mathrm{P}$ \\
\hline Intercept & 438,0 & 53,1 & $* * *$ & 8,3 & 0,0001 \\
Happy & 127,2 & 53,4 & $* *$ & 2,4 & 0,0283 \\
Sad & $-13,0$ & 132,5 & & $-0,1$ & 0,9231 \\
Angry & 35,4 & 181,2 & & 0,2 & 0,8473 \\
Fear & 81,0 & 132,5 & 0,6 & 0,5486 \\
Worry & $-16,5$ & 77,5 & $-0,2$ & 0,8334 \\
Confident & 65,9 & 63,5 & 1,0 & 0,3133 \\
Excited & 108,7 & 84,4 & 1,3 & 0,2141 \\
Self-Control & 40,6 & 57,7 & 0,7 & 0,4908 \\
\hline R-Square & $33,73 \%$ & & & \\
Adj. R-Square & $4,27 \%$ & & & & \\
F Value & 1,15 & & & \\
p Value & 0,3818 & & & \\
Observations & 27 & & &
\end{tabular}

I also repeated the study with separate sample sub-groups for the investor and manager roles. The findings show that profitability of investors and managers are dependent on their emotional status. Table 5 shows that the investor's profitability seem to be positively effected by his happiness. The manager's profitability is reported on Table 6, where the happy and fearful managers seem to have statistically significant higher profitability compared to other emotions. The link between profitability and happiness seem to be supported here as well. The results seem to indicate also that the angry managers have lower profitability.

Table 6: Regression of Manager's Total Profit on Emotional State

\begin{tabular}{lccccr}
\multicolumn{1}{c}{ Variable } & \multicolumn{2}{c}{ ParameterStandard Error } & \multicolumn{1}{c}{ Value } & \multicolumn{1}{c}{$\mathrm{P}$} \\
\hline Intercept & 489,0 & 58,3 & $* * *$ & 8,4 & 0,0001 \\
Happy & 139,0 & 60,9 & $* *$ & 2,3 & 0,0335 \\
Sad & 82,0 & 105,1 & & 0,8 & 0,447 \\
Angry & $-194,0$ & 105,1 & $*$ & $-1,9$ & 0,0798 \\
Fear & 397,0 & 162,4 & $* *$ & 2,5 & 0,0239 \\
Worry & $-72,0$ & 85,0 & & $-0,9$ & 0,4067 \\
Confident & $-12,3$ & 69,9 & & $-0,2$ & 0,8621 \\
Excited & 32,5 & 57,2 & & 0,6 & 0,5768 \\
Self-Control & 67,7 & 49,8 & & 1,4 & 0,1896 \\
\hline R-Square & $62,58 \%$ & & & & \\
Adj. R-Square & $47,62 \%$ & & & & \\
F Value & 4,18 & & & & \\
p Value & 0,0045 & & & & \\
Observations & 29 & & & &
\end{tabular}

The findings support previous findings of Capra (2004), where happy mood people act more strategically on a previous study. It can be concluded that the emotion of being happy has a directional effect on the profitability of capital market players, although this cannot be modeled to describe profitability as a whole through the regression estimates.

\section{Conclusion}

This analysis is to investigate the emotional aspect of the capital market decisions on profitability where shareholder and manager mechanism is replicated on experimental set-up. The investor and manager behavior is analyzed and the profitability of investors and managers seem to be found to be dependent on their emotional status. Although there is some research investigating the link of emotions with investor's willingness to pay, 
there is no research which can relate emotions to profitability. The interdisciplinary study of the emotions with financial decisions in behavioral finance is an area which is not investigated in depth by the academia. This study is motivated by the urge to establish and prove such a link for the emotions happiness, fearfullness, angriness and excitedness. The results show that there seems to be a statistically significant positive link between a person's happiness and his profitability in the capital market area. Although for the feeling of happiness, we can confirm that the finding is significant, the sample size may not be large enough to prove any further highly statistically significant feelings' link to profitability. Hence, there is some significance of a person's fear and excitement on profitability again positively.

The shortcoming of this study is that the capital market environmant was only replicated with one asset and the future research may establish a more close to real market replication. Future research should also consider to have a more detailed analysis with real stock market investors with mood elicitation techniques as this will be the next step to search for a link with major emotions. The findings may help both investors and regulators to establish a more rational investment style for the investors by learning their deficiencies whereby they overcome their disabilities in decision-making process on the road to better governance of the market 


\section{References}

1. Adler, Jerry "Mind Reading-The New Science of Decision Making. It's Not As Rational As You Think" Newsweek, July 2004

2. Capra, Monica, Shireen Meer and Kelli Lanier "The Effects of Induced Mood on Bidding in Random N-th Price Auctions" (March 2008)

3. Capra, Monica "Mood-Driven Behavior in Strategic Interactions", American Economic Review , 94(2), P\&P May 2004, 387-372

4. Camerer, Colin, George Loewenstein and Drazen Prelec "Neuroeconomics:How Neuroscience Can Inform Economics”, Journal of Economic Literature, Vol. XVIII (March 2005) pp.9-64

5. Cassidy, John "Mind Games" The New Yorker September 2006

6. Charness, Gary and Uri Gneezy "Portfolio Choiceand Risk Attitudes:An Experiment" (February 2003) JEL

7. Easley, David and Aldo Rustichini “Choice without Beliefs" (1998)

8. Engelmann JB, Capra CM, Noussair C, Berns GS, 2009 Expert Financial Advice Neurobiologically “Offloads” Financial Decision-Making under Risk. PLoS ONE 4(3): e4957.

9. doi:10.1371/journal.pone.0004957Fischbacher, Urs “z-tree Program”, https://www.uzh.ch/iew/ztree/ss1dir/wiki/index.php?n=Main.NewInVersion3, 2007

10. Hofbauer, Josef and Schlag, Karl H. "Sophisticated imitation in cyclic games" Journal of Evolutionary Economics Volume 10, Number 5, 523-543, 2000

11. Johnson, Eric and Tversky, Amos. "Affect, Generalization, and the Perception of Risk." Journal of Personality and Social Psychology, July 1983, 45(1), pp. 20-31

12. Lerner, Jennifer S., Small, Deborah A., \& Loewenstein, George (2004) "Heart strings and purse strings: Carryover effects of emotions on economic decisions" Psychological Science, 15(5), 337-341

13. Lo, Andrew W., Dimitry V. Repin and Brett N. Steenbarger "Fear and Greed in Financial Markets: A Clinical Study of Day-Traders" Cognitive Neuroscientific Foundations of Economic Behavior, Vol. 95 No. 2 (May 2005)

14. Lo, Andrew W., Dimitry V. Repin “The Psychophysiology of Real-Time Financial Risk Processing” Journal of Cognitive Neuroscience, Vol. 14, No. 3 323-339, (2002)

15. Loewenstein, George (1996) “Out of Control:Visceral Influences on behavior” Organizational Behavior and Human Decision Processes, 65, 272-92. 
16. Loewenstein, George, Weber, E., Hsee, C. \& Welch, N. (2001) "Risk as Feelings" Psychological Bulletin $127,267-286$.

17. Powell, Kendall "Economy of the Mind" PLoS Biology, Volume 1 Issue 3

18. Raghunathan, Rajagopal and Pham, Michel Tuan “All Negative Moods Are Not Equal: Motivational Influences of Anxiety and Sadness on Decision Making," Organizational Behavior and Human Decision Processes, 1999, 79 (1), 56-77.

19. Rustichini, Aldo "Emotion and Reason in Making Decisions" Science, Vol. 310, December 2005

20. Singer, Tania and Fehr, Ernst "The Neuroeconomics of Mind Reading and Empathy" The American Economic Review, Vol. 95, No. 2, Papers and Proceedings of the One Hundred Seventeenth Annual Meeting of the American Economic Association, Philadelphia, PA, January 7-9, 2005 (May, 2005), pp. 340345

21. Shefrin, Hersh "Beyond Greed and Fear", Chapter 9, Oxford University Press, 2002

22. Schleifer, "Inefficient Markets" Chapter 1,

23. Smith, Vernon, Mark van Boening and Charissa P. Wellford "Dividend Timing and Behavior in Laboratory and Asset Markets", Economic Theory 16, 567-583, (2000)

24. Witteloostujin, Arjen Van and Katrin Muehlfield "Trader Personality and Trading Performance", 2008

25. Van Boven, Leaf, Loewenstein, George, \& Dunning, David "The illusion of courage in social predictions: Underestimating the impact of fear of embarrassment on other people" Organizational Behavior and Human Decision Processes, Volume 96, Issue 2, March 2005, Pages 130-141 


\section{Appendix}

\begin{tabular}{llc}
\multicolumn{1}{c}{ Treatment } & \# Subjects & \# Rounds \\
\hline \hline $\begin{array}{l}\text { "Dividend Before." Dividend } \\
\text { announced before trading }\end{array}$ & 24 & 10 \\
$\begin{array}{l}\text { "Dividend After." Dividend } \\
\text { announced after trading }\end{array}$ & 30 & 10 \\
$\begin{array}{l}\text { "Investor Control." Dividend } \\
\text { decided by the Investor }\end{array}$ & 20 & 10 \\
\hline
\end{tabular}

Table VII. Experiment Design

\section{SURVEY}

Please answer these questions.
Age:
Gender:
Major:

1. What do you estimate the level of the Dow Jones Industrial Average will be at closing on March 31, 2009 ?

2. How do you describe your current emotional state? (Circle all that apply)
A. happy
B. $\mathrm{sad}$
C. angry
D. fearful
E. worried
F. confident
G. excited
H. self-controlled

3. How do you rate yourself generally?
1
2
34
56
7
Optimistic
Neither
Pessimistic 
4. Did you have an experience, which made you either very happy or very sad in the last two days?
a)Yes
b)No

4.1 Which of the below statements describe you better? On a 1-7 scale, please select the choice, which applies more to you.

5. Do you think that you make decisions logically or emotionally?

\begin{tabular}{crrrrrr}
1 & 2 & 3 & 4 & 5 & 6 & 7 \\
Logical & & Stable & & \multicolumn{2}{c}{ Emotional }
\end{tabular}

6. Are you more extraverted (outgoing) or introverted (shy)?

$\begin{array}{lllllll}1 & 2 & 3 & 4 & 5 & 6 & 7\end{array}$

Extraverted Stable Introverted

7. Are you a person, who loses his/her temper easily?

\begin{tabular}{rrrrrrrr}
1 & 2 & 3 & 4 & 5 & 6 & 7 & \\
Yes & \multicolumn{3}{c}{ Neither } & & & &
\end{tabular}

8. Do you think that you make good decisions in situations of uncertainty?

\begin{tabular}{rrrrrrrrr}
1 & 2 & 3 & 4 & 5 & 6 & 7 & \\
Yes & \multicolumn{1}{c}{ Neither } & & & & & & & No
\end{tabular}

9. Are you generally a risk-taker or risk-avoider?

$\begin{array}{lllllll}1 & 2 & 3 & 4 & 5 & 6 & 7\end{array}$

Risk-taker Neither Risk-avoider

10.Have you ever bought individual stocks?
a)Yes
b)No 